\title{
The Virulence of Biochemical Mutants of Erwinia aroideae for Varieties of Radish and Turnip
}

\author{
By E. D. GARBER, SUSAN G. SHAEFFER AND M. GOLDMAN \\ Department of Botany, The University of Chicago, Chicago, Ill., U.S.A.
}

SUMMARY: Biochemical mutants of Erwinia aroideae displayed a pattern of virulence and avirulence for varieties of radish and turnip similar to the pattern previously reported for different host species. Three types of host response were noted when slices of the fleshy storage organs were inoculated: uniformly resistant, uniformly susceptible, and a variable response in which individuals of a given variety may be resistant or susceptible to a specific mutant. Prototrophic reversions from an avirulent mutant requiring arginine and from an uncharacterized mutant with diminished virulence were as virulent as the parental strain for all varieties of radish and turnip.

Pathogenicity may be defined as a specific expression of a host-parasite relationship in which the host serves as an environment for the parasite. The property of pathogenicity with respect to the parasite assumes that the parasite is capable of utilizing the host environment as a growth medium and that the parasite can overcome the host's defence mechanisms. It should be noted that two problems are involved: the ability of the parasite to proliferate or to metabolize extensively and mechanism(s) whereby the parasite damages the host either in toto or in specific tissues or cells of the host. The first problem has been relatively neglected. The role of nutrition in the host-parasite relationship may be referred to the nutritional requirements of the parasite as they may or may not be satisfied by the host environment.

Recent studies with biochemical mutants of animal and plant pathogens have indicated that mutants with specific nutritional requirements may be avirulent if the host environment does not supply an adequate concentration of the required nutrilites, either at the site of inoculation or of localization (Bacon, Burrows \& Yates, 1951; Garber, Hackett \& Franklin, 1952; Garber, 1954; Keitt \& Boone, 1954). Garber (1954) observed that certain biochemical mutants of Erwinia aroideae were not uniformly virulent for a given host species, and assumed that the variation in virulence may have resulted from the inadvertant usage of different varieties of the host species. This report presents data on the virulence of biochemical mutants of $E$. aroideae for a number of varieties of radish and turnip.

\section{METHODS}

Erwinia aroideae, strain RK (Garber \& Hackett, 1954), is a bacterial plant pathogen producing a soft rot in the fleshy storage organs of numerous vegetable species. Organisms were grown in A medium (Davis \& Mingioli, 1950) at $27^{\circ}$ with constant shaking for $24 \mathrm{hr}$. The culture was serially diluted in 
$0 \cdot 8 \%(\mathrm{w} / \mathrm{v}) \mathrm{NaCl}$ to yield a suspension containing $1-4 \times 10^{4}$ viable organisms $/ \mathrm{ml}$. Ten ml. of this suspension were placed in a sterile Petri dish and irradiated for the desired length of time by means of a General Electric 'Sterilamp' (15 W.) at a standardized distance so that the dosage was approximately 300 ergs. The dish was agitated gently during the period of exposure. Samples $(0 \cdot 1 \mathrm{ml}$.) of irradiated organisms were inoculated into $9 \mathrm{ml}$. of nutrient broth (Difco), supplemented with $0 \cdot 1 \%$ yeast extract (Difco) and incubated at $27^{\circ}$ with constant shaking for $\mathbf{2 4} \mathrm{hr}$. with suitable precautions against photoreactivation (Kelner, 1949). The cultures were centrifuged, washed with $0 \cdot 8 \% \mathrm{NaCl}$ twice, resuspended in A medium containing 300 units of penicillin $/ \mathrm{ml}$., and incubated at $27^{\circ}$ for $24 \mathrm{hr}$. Samples $(0 \cdot 1 \mathrm{ml}$.) were then plated on nutrient agar (Difco) supplemented with $0 \cdot 1 \%$ yeast extract and incubated at $27^{\circ}$ for $48 \mathrm{hr}$. Colonies selected at random were picked and inocula were added to a plate containing A medium solidified with Noble agar (Difco) and to a plate containing nutrient agar supplemented with yeast extract. Colonies failing to grow on the A medium were retested on this medium. Nutritional requirements were determined auxanographically (Pontecorvo, 1949) using commercially available amino acids, vitamins, growth factors, purines, and pyrimidines. Once a mutant was characterized, no attempt was made to establish the specific site or nature of the nutritional block. Thirty biochemical mutants were isolated, all but one requiring one or more amino acids. Four mutants were not characterized completely but they required one or more amino acids.

To prepare inocula for the virulence tests, the parental and mutant strains were grown in nutrient broth supplemented with $0 \cdot 1 \%$ yeast extract at $27^{\circ}$ with constant shaking for $24 \mathrm{hr}$. The cultures were centrifuged, washed with $0.8 \% \mathrm{NaCl}$, and resuspended in $0.8 \% \mathrm{NaCl}$ to yield a suspension containing $1-4 \times 10^{9}$ viable organisms $/ \mathrm{ml}$. These suspensions were then incubated at $27^{\circ}$ with constant shaking for $4 \mathrm{hr}$. The surface of slices of the fleshy storage organs of the host was inoculated with $0.05 \mathrm{ml}$. of this suspension.

Seed of nine varieties of radish and three varieties of turnip were purchased from the W. Atlee Burpee Co., Philadelphia, Pennsylvania, U.S.A., who also provided the varietal names. Mature plants were harvested and the fleshy storage organs were washed with tap water, immersed in a $20 \%(\mathrm{v} / \mathrm{v})$ solution of 'Chlorox' for 3-5 min., and rinsed with sterile, distilled water. The fleshy organs were then sliced with a sterile knife, the slices being placed in a sterile Petri dish containing a saturated layer of filter-paper. The slices were inoculated by dropping the bacterial suspension on the upper surface and then incubated at $27^{\circ}$ for $24 \mathrm{hr}$. A slice from at least three different plants of each variety was used in routine tests of virulence and, in some experiments, as many as nine plants were used. After incubation, slices which had been attacked displayed a discoloured, slimy, glistening surface which was easily penetrated by a blunt, glass rod; slices which had not been attacked remained white and firm. Suitable controls were routinely used. Since preliminary experiments consistently yielded cells of the inoculated strain, re-isolation of the mutants from attacked slices was not routinely done. 
Three types of response were noted when plants of a given variety were inoculated with the biochemical mutants: uniformly resistant, uniformly susceptible, and a variable response, i.e. some resistant and some susceptible individuals in a given variety. Slices from a single, fleshy organ displayed a uniform response when inoculated with a given biochemical mutant.

\section{RESULTS}

The radish as host. Relatively few mutants appeared to have lost their virulence for the radish (Table 1). Both mutants requiring arginine were avirulent for all nine varieties. The four mutants which were not fully characterized displayed either avirulence or a greatly diminished virulence for all nine varieties. The mutants requiring isoleucine and valine exhibited a striking pattern of virulence and avirulence. Although the mutants requiring cysteine, histidine or glycine also showed a pattern of virulence and avirulence, the differences among these mutants were relatively minor.

Since it had been demonstrated that prototrophic reversions from an avirulent biochemical mutant of Erwinia aroideae would be virulent (Garber \& Hackett, 1954), a similar demonstration was attempted with a mutant requiring arginine (21-1-1) and a mutant (35-7-57) which had not been fully characterized. Two independent prototrophic reversions from mutant 21-1-1 and three independent prototrophic reversions from mutant 35-7-57 were as virulent as the parental strain for all nine varieties.

The possible effect of a high reversion rate on the virulence tests was determined. Mutants which were virulent for all nine varieties were tested for their frequency of prototrophic reversions by plating $c .1 \times 10^{8}$ viable organisms on solidified A medium. Only mutant 19-8-40 requiring cysteine and mutant 20-1-51 requiring methionine had a high frequency of reversions. Repeated virulence tests using numbers of viable organisms of these mutants, adjusted to make unlikely the inclusion of reversions, confirmed the original observations that these mutants were uniformly virulent for all varieties.

Mutants displaying a variable virulence for certain varieties were further tested by inoculating slices from additional plants of these varieties. The results summarized in Table 2 indicated that not all plants in these varieties responded uniformly. In some combinations of mutant and variety, c. 50\% of the plants were resistant and the remainder, susceptible.

The turnip as host. The pattern of virulence and avirulence of the mutants for the three varieties of turnip paralleled to a considerable extent the pattern noted for the radish varieties (Table 3). Both mutants requiring arginine were avirulent for all three varieties. The four mutants which could not be fully characterized likewise were avirulent with a single exception. Whereas the mutants requiring cysteine or glycine remained comparatively virulent, the mutants requiring histidine or isoleucine and valine were greatly diminished in their virulence. Specific mutants able to attack many radish varieties were not virulent for all the turnip varieties.

As was the case in the virulence tests using the radish varieties, certain 


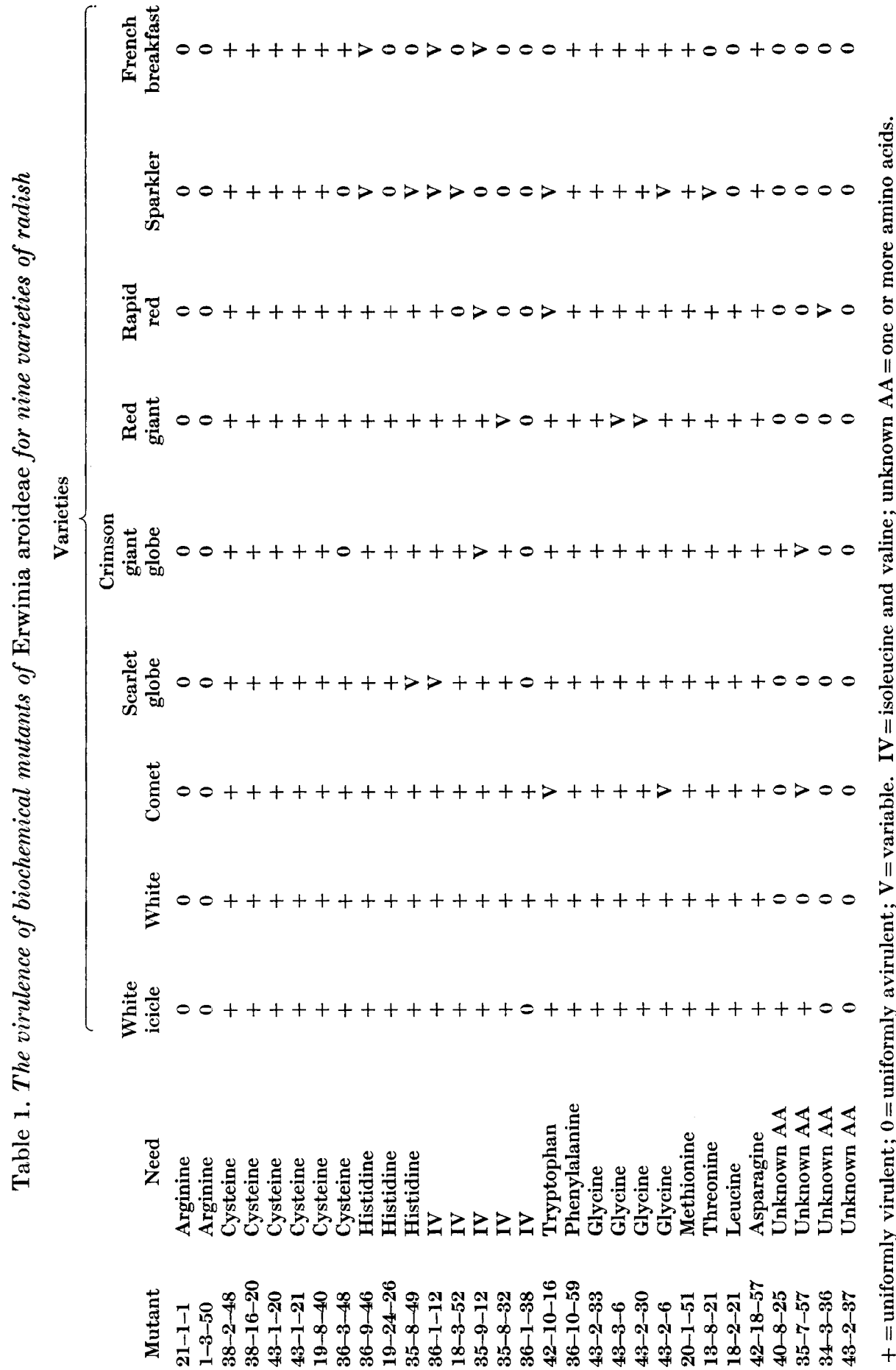


Table 2. The response of individual plants of varieties of radish to certain biochemical mutants of Erwinia aroideae

\begin{tabular}{|c|c|c|c|c|c|c|c|c|c|c|c|c|c|c|c|}
\hline \multirow[b]{3}{*}{ Mutant } & \multirow[b]{3}{*}{ Need } & \multicolumn{14}{|c|}{ Varieties } \\
\hline & & \multicolumn{2}{|c|}{ Comet } & \multicolumn{2}{|c|}{$\begin{array}{l}\text { Scarlet } \\
\text { globe }\end{array}$} & \multicolumn{2}{|c|}{$\begin{array}{l}\text { Crimson } \\
\text { Giant } \\
\text { globe }\end{array}$} & \multicolumn{2}{|c|}{$\begin{array}{l}\text { Red } \\
\text { giant }\end{array}$} & \multicolumn{2}{|c|}{$\underset{\text { red }}{\text { Rapid }}$} & \multicolumn{2}{|c|}{ Sparkler } & \multicolumn{2}{|c|}{$\begin{array}{c}\text { French } \\
\text { breakfast }\end{array}$} \\
\hline & & $\mathbf{S}$ & $\mathbf{R}$ & $\mathbf{S}$ & $\mathbf{R}$ & $\mathbf{S}$ & $\mathbf{R}$ & $\mathbf{S}$ & $\mathbf{R}$ & $\mathbf{S}$ & $\mathbf{R}$ & $\mathbf{S}$ & $\mathbf{R}$ & $\mathrm{s}$ & $\mathbf{R}$ \\
\hline $36-9-46$ & Histidine & . & . & . & . & . & . & . & . & . & . & 6 & 2 & 5 & 4 \\
\hline $35-8-49$ & Histidine & . & . & 4 & 5 & . & . & . & . & . & . & 3 & 6 & . & . \\
\hline $36-1-12$ & IV & . & . & 3 & 5 & . & . & . & . & . & . & 5 & $\mathbf{3}$ & 5 & 4 \\
\hline $18-3-52$ & IV & . & . & . & . & . & . & . & . & . & . & 4 & 5 & . & . \\
\hline $35-9-12$ & IV & . & . & . & . & 5 & 4 & . & . & 3 & 5 & . & . & 2 & 6 \\
\hline $35-8-32$ & IV & . & . & . & . & . & . & 2 & 6 & . & . & . & . & . & . \\
\hline $42-10-16$ & Tryptophan & 4 & 5 & . & . & . & . & & 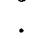 & 7 & 2 & 5 & 3 & . & . \\
\hline $43-3-6$ & Glycine & . & . & . & . & . & . & $i$ & 2 & . & . & . & . & . & . \\
\hline $43-2-30$ & Glycine & . & . & . & . & . & . & 4 & 5 & . & . & . & . & . & . \\
\hline $43-2-6$ & Glycine & 4 & 2 & . & . & . & . & . & . & . & . & 5 & 1 & . & . \\
\hline 13-8-21 & Threonine & . & . & . & . & . & 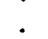 & . & . & . & . & 6 & 2 & . & . \\
\hline $35-7-57$ & Unknown AA & 4 & 1 & . & . & 4 & 5 & . & . & . & . & . & . & . & . \\
\hline $34-3-36$ & Unknown AA & . & . & . & . & . & . & . & . & 1 & 4 & . & . & . & . \\
\hline
\end{tabular}

Table 3. The virulence of biochemical mutants of Erwinia aroideae for three varieties of turnip Varieties

\begin{tabular}{|c|c|c|c|c|}
\hline Mutant & Need & $\begin{array}{l}\text { Extra early purple } \\
\text { top Milan }\end{array}$ & $\begin{array}{l}\text { Purple top white } \\
\text { globe }\end{array}$ & Foliage \\
\hline 21-1-1 & Arginine & 0 & 0 & $\mathbf{0}$ \\
\hline $1-3-50$ & Arginine & 0 & 0 & 0 \\
\hline $38-2-48$ & Cysteine & + & + & + \\
\hline $38-16-20$ & Cysteine & + & + & + \\
\hline $43-1-20$ & Cysteine & + & + & + \\
\hline $43-1-21$ & Cysteine & + & + & + \\
\hline $19-8-40$ & Cysteine & + & + & + \\
\hline $36-3-48$ & Cysteine & V & 0 & 0 \\
\hline $36-9-46$ & Histidine & + & 0 & 0 \\
\hline 19-24-26 & Histidine & + & $\mathbf{0}$ & 0 \\
\hline $35-8-49$ & Histidine & + & 0 & 0 \\
\hline $36-1-12$ & IV & v & $\mathbf{v}$ & $\mathbf{V}$ \\
\hline $18-3-52$ & IV & $\mathrm{V}$ & 0 & 0 \\
\hline $35-9-12$ & IV & + & V & 0 \\
\hline $35-8-32$ & IV & v & V & 0 \\
\hline $36-1-38$ & IV & $\mathbf{v}$ & 0 & 0 \\
\hline $42-10-16$ & Tryptophan & + & + & V \\
\hline $36-10-59$ & Phenylalanine & + & + & + \\
\hline $43-2-33$ & Glycine & + & + & + \\
\hline $43-3-6$ & Glycine & + & + & + \\
\hline $43-2-30$ & Glycine & + & + & + \\
\hline $43-2-6$ & Glycine & V & + & + \\
\hline $20-1-51$ & Methionine & + & + & + \\
\hline $13-8-21$ & Threonine & V & 0 & 0 \\
\hline $18-2-21$ & Leucine & + & + & V \\
\hline $42-18-57$ & Asparagine & + & + & + \\
\hline $40-8-25$ & Unknown AA & 0 & 0 & 0 \\
\hline $35-7-57$ & Unknown AA & V & 0 & 0 \\
\hline $34-3-36$ & Unknown AA & $\mathbf{0}$ & $\mathbf{0}$ & 0 \\
\hline $43-2-37$ & Unknown AA & $\mathbf{0}$ & 0 & 0 \\
\hline
\end{tabular}

$+=$ uniformly virulent $; 0=$ uniformly avirulent; $V=$ variable. $I V=$ isoleucine and valine ; unknown $\mathrm{AA}=$ one or more amino acids. 
combinations of mutant and turnip variety yielded a variable virulence. Further tests with these combinations confirmed the original observations (Table 4).

Table 4. The response of individual plants of varieties of turnips to certain biochemical mutants of Erwinia aroideae

\begin{tabular}{|c|c|c|c|c|c|c|c|}
\hline \multirow[b]{3}{*}{ Mutant } & \multirow[b]{3}{*}{ Need } & \multicolumn{6}{|c|}{ Varieties } \\
\hline & & \multicolumn{2}{|c|}{$\begin{array}{c}\text { Extra early } \\
\text { purple top } \\
\text { Milan }\end{array}$} & \multicolumn{2}{|c|}{$\begin{array}{l}\text { Purple top } \\
\text { white globe }\end{array}$} & \multicolumn{2}{|c|}{ Foliage } \\
\hline & & $\mathbf{S}$ & $\mathbf{R}$ & $\mathbf{S}$ & $\mathbf{R}$ & $\mathbf{S}$ & $\mathbf{R}$ \\
\hline $36-3-48$ & Cysteine & 5 & 4 & . & . & . & . \\
\hline $36-1-12$ & IV & 5 & 3 & 5 & 3 & . & . \\
\hline $18-3-52$ & IV & 7 & 2 & . & . & $\mathbf{3}$ & 6 \\
\hline $35-9-12$ & IV & . & . & 5 & 3 & . & . \\
\hline $35-8-32$ & IV & $\mathbf{5}$ & 3 & 3 & 6 & . & . \\
\hline $36-1-38$ & IV & 3 & 5 & . & . & . & . \\
\hline $42-10-16$ & Tryptophan & . & . & . & . & 4 & 5 \\
\hline $13-8-21$ & Threonine & 4 & 5 & . & . & . & . \\
\hline $18-2-21$ & Leucine & . & . & - & . & 7 & 2 \\
\hline $43-2-6$ & Glycine & 5 & 1 & . & . & . & . \\
\hline $35-7-57$ & Unknown AA & 7 & $\mathbf{2}$ & . & . & . & . \\
\hline
\end{tabular}

$\mathrm{S}=$ susceptible $; \mathrm{R}=$ resistant. $\mathbf{I V}=$ isoleucine and valine; unknown $\mathrm{AA}=$ one or more amino acids.

\section{DISCUSSION}

The biochemical mutants of Erwinia aroideae exhibited a pattern of virulence and avirulence for varieties of radish and turnip similar to that previously reported for different host species (Garber, 1954). This pattern which had been interpreted as an expression of the relationship between the demand for required nutrilites by the parasite and the supply of these nutrilites by the host, either at the site of inoculation or of localization, may now be extended from the species level to the variety level. It should be emphasized that an 'inadequate' supply does not imply an absence of the required nutrilite (Garber, 1954). The resistance or susceptibility of varieties or species to specific biochemical mutants may reflect different concentrations of the required nutrilites in the hosts. A similar interpretation may be offered for the variable response of individuals in a variety. Supporting evidence must come from an in vitro demonstration of different concentrations of the required nutrilites (in the amino acid content) among the varieties of radish and turnip.

This investigation was generously supported by a contract (NR 135-267) between the Office of Naval Research, Department of the Navy, and The University of Chicago, and by a grant from the Dr Wallace C. and Clara A. Abbott Memorial Fund of the University of Chicago.

\section{REFERENCES}

Bacon, G. A., Burnows, T. W. \& Yates, M. (1951). The effects of biochemical mutation on the virulence of Bacterium typhosum: the loss of virulence of certain mutants. Brit. J. exp. Path. 32, 85. 
Davis, B. D. \& Mingioli, E. S. (1950). Mutants of Escherichia coli requiring methionine or vitamin B12. J. Bact. 60, 17.

Garber, E. D. (1954). The role of nutrition in the host-parasite relationship. Proc. nat. Acad. Sci., Wash., 40, 1112.

Garber, E. D. \& HacketT, A. J. (1954). The virulence of auxotrophic mutants of Erwinia aroideae. Nature, Lond., 173, 88.

Garber, E. D., Hackett, A. J. \& Franklin, R. (1952). The virulence of biochemical mutants of Klebsiella pneumoniae. Proc. nat. Acad. Sci., Wash., 38, 693.

KeIrT, G. W. \& BoonE, D. M. (1954). Induction and inheritance of mutant characters in Venturia inaequalis in relation to its pathogenicity. Phytopathology, 44, 362.

Kelner, A. (1949). Photoreactivation of ultraviolet-irradiated Escherichia coli with special reference to the dose-reduction principle and to ultraviolet induced mutation. J. Bact. 58, 511.

Ponteconvo, G. (1949). Auxanographic techniques in biochemical genetics. J. gen. Microbiol. 3, 122.

(Received 19 August 1955) 